\title{
Beer Brewing and the Environmental Engineer: "Tapping" into Experiential Learning
}

\section{Major Kyle R. Murray, United States Military Academy}

Kyle Murray is a Major and an Aviation Officer in the United States Army and an Instructor in the Department of Geography and Environmental Engineering at the United States Military Academy. He is a 2007 graduate of the United States Military Academy with a B.S. in Civil Engineering and graduated from the University of California - Los Angeles (UCLA) with an M.S. in Environmental Engineering in 2017. His research interests include wastewater treatment technologies and microbiology as well as air pollution mitigation and control technologies. His current research focuses on engineering education in the field of environmental engineering. He teaches courses in Environmental Biological Systems, Environmental Science, Environmental Engineering Technologies, and Environmental Chemistry. He is also a licensed Professional Engineer in the state of Delaware.

\section{Dr. Benjamin Michael Wallen P.E., United States Military Academy}

Benjamin Wallen is a Lieutenant Colonel in the United States Army and an Assistant Professor in the Department of Geography and Environmental Engineering at the United States Military Academy. He is a 1996 graduate of the United States Military Academy with a B.S. in Environmental Engineering, and he obtained an M.S. from the University of Missouri at Rolla in Geological Engineering in 2000, an M.S. from the University of Texas at Austin in Environmental Engineering in 2005, and a Ph.D. from the Colorado School of Mines in Civil and Environmental Engineering in 2016. He course directs and teaches Environmental Science for Engineers and Scientists, Environmental Engineering Technologies, and Advanced Individual Study I-II.

\section{Capt. Luke Plante, United States Military Academy}

Luke Plante is a Captain in the United States Army and an Assistant Professor in the Department of Geography and Environmental Engineering at the United States Military Academy. He is a 2008 graduate of the United States Military Academy with a B.S. in Environmental Engineering and graduated from Columbia University with an M.S. in Environmental Engineering in 2016. He teaches Environmental Biological Systems, Environmental Science, Environmental Engineering Technologies, Introduction to Environmental Engineering, Advanced Individual Study I-II, Biochemical Treatment, and Officership.

\section{Kimberly Quell, United States Military Academy}

Kimberly Quell is a Laboratory Technician in the Department of Geography and Environmental Engineering at the United States Military Academy. She is a 2010 graduate of SUNY-College of Environmental Science and Forestry with a B.S. in Environmental Science and is a currently attending graduate school at Stevens Institute of Technology for an M.E. in Environmental Engineering. She is the lead laboratory technician for the Environmental Biological Systems course, the Environmental Science Curriculum, and the USMA Environmental Engineering Sequence Curriculum.

\section{Dr. Michael A. Butkus, United States Military Academy}

Michael A. Butkus is a professor of environmental engineering at the U.S. Military Academy. His work has been focused on engineering education and advancements in the field of environmental engineering. His current research interests are in physicochemical treatment processes with recent applications in drinking water disinfection, lead remediation, sustainable environmental engineering systems, and contaminant transport. Dr. Butkus is a Board Certified Environmental Engineer and he is a registered Professional Engineer in the state of Connecticut. 


\title{
Beer Brewing and the Environmental Engineer: “Tapping” into Experiential Learning
}

\begin{abstract}
Second to water, beer may perhaps be the next most desirable beverage in the lives of countless environmental engineering students. But do they fully understand or appreciate the engineering and scientific principles behind beer making? While considerable effort has been put forth in academia to teach and explain the critical environmental process of fermentation, too many students are limited to examples and explanations contained within a course textbook. The United States Military Academy is committed to providing experiential learning opportunities that reach beyond traditional classroom instruction. Our Environmental Biological Systems Course (EV396) offers an opportunity for environmental engineers to achieve a deeper, more practical understanding and appreciation for biological systems within our environment. As part of the experiential learning process, EV396 requires students to successfully brew beer in a laboratory setting to enhance their understanding of microbial metabolic processes, disinfection principles, and aseptic techniques. This paper aims to highlight and explain the linkage between the complex process of alcoholic fermentation involved in beer brewing to the environmental engineering practice. Indeed, environmental engineers often face challenges where they must design and operate biological systems and apply engineering concepts like those integral to brewing beer, including conventional wastewater management, microbial fuel cells, hazardous waste treatment and remediation, slow sand filtration, and disinfection. As part of this fermentation laboratory experience, students select the style of beer they wish to brew and exercise the engineered techniques required to brew a safe and refreshing product. Additionally, students are required to submit a detailed report demonstrating their ability to identify and evaluate key physiochemical and biochemical engineering processes. Calculations involve fermentation efficacy, specific gravity and yield, theoretical and actual ethanol content, and scaling from bench experiments to commercial production. The laboratory familiarizes students with engineering concepts, including substrates that serve as carbon and energy sources, methods for creating anaerobic reactors, and solid-liquid separation processes. Using the 5-point Likert scale, with 5 indicating greatest achievement, student laboratory performance scores are consistently greater than 3 and many are above 4 , indicating effective learning, application, and understanding. Historical assessment and evaluation of how well this experiential learning laboratory supports course objectives and ABET Student Outcomes and Program Criteria are discussed in detail.
\end{abstract}

\section{Keywords}

Environmental engineering education, engineering education, experiential learning, laboratory experience, beer brewing, fermentation 


\section{Introduction}

Environmental engineering requires individuals who can adapt, innovate, and create new, exciting solutions to help solve complex problems throughout our natural environment. Powerful learning experiences exist when students have an opportunity to learn by application, while also having fun by creating excitement around the subject material. Indeed, that is why most curricula include other experiences beyond the classroom such as laboratories, field trips, seminars, design projects and modeling projects [1, 2]. An esteemed scientist and statesman said it best:

\section{'Tell me and I forget. Show me and I may remember. Involve me and I understand.'}

\section{- Benjamin Franklin}

Besides being an important cultural and social tradition in different parts of the world, brewing alcohol for consumption involves a scientific process using fundamentals from chemistry and biology. In particular, the process of brewing beer depends mainly on microbial interactions with chemical constituents in their surrounding environment. As the added ingredients undergo a series of chemical transformations, including glycolysis, microbial species carry out fermentative processes to produce ethanol, the foundation of the final beer product.

The application of brewing beer ranges from large-scale commercial manufacturing for the population to home-scale brewing for individual production and consumption. The process and procedures for brewing beer have become fairly standardized and simple enough to apply in an academic setting. For instance, brewing beer can be done as a laboratory exercise, providing students with an experiential learning opportunity involving scientific fundamentals. This academic application allows students to actively observe, influence, and experience important environmental processes such as glycolysis and fermentation.

Several programs in the STEM field have been using brewing-related topics as a focus of experiential learning at a variety of institutions [3, 4]. For instance, Purdue University implemented a laboratory course titled "Brewing Science," which utilizes various experiments to mimic the brewing process, helping to illustrate science for its students [5]. Likewise, in Serbia, high-school students were exposed to a beer brewing exercise to enhance their learning of chemistry fundamentals and provide an opportunity for application of their chemistry knowledge [6]. Rowan University (R.U.) engineering students complete a series of hands-on engineering and design projects, one of which investigates the reverse-engineering of the fermentation process and home-brewing equipment, to better understand engineering design fundamentals [7]. Pelter [8] discusses how hands-on experiments involving beer brewing can be a means to attract and engage college students from non-science majors in a chemistry laboratory. Other institutions have used techniques like video games [2] to pique student interest. Hooker [9] further discusses the use of a laboratory-based beer brewing course covering the biology and chemistry involved in this process, giving students experiential learning opportunities to apply chemistry and biology fundamentals. Like the use of video games [2], brewing beer can focus students on achieving a tangible goal. Some students may learn from a video game as they competitively try to win, just as other students focus on beer brewing and the related scientific fundamentals to achieve the goal of producing a good beer product.

The United States Military Academy (West Point) strives to provide students a variety of experiential learning opportunities throughout their four-year academic curriculum. West Point 
seeks to develop Army officers who are critical and agile thinkers, capable of developing innovative and adaptive solutions to challenging real-world problems. The current undergraduate ABET accredited Environmental Engineering Program curriculum at West Point is designed to produce Army leaders who have the requisite skills to not only be competent environmental engineers, but also critical thinkers and innovative problem solvers. Because most graduates of the program do not immediately practice environmental engineering upon graduation, the program aims to provide our graduates with a broad background in the field, with a focus on fundamental principles.

The ABET program criterion for environmental engineering states that students must have proficiency in a biological science, e.g., microbiology, aquatic biology, or, toxicology, relevant to the program of study. In addition, traditional courses in biochemical treatment processes (e.g. domestic wastewater treatment) may not satisfy this ABET biological science requirement because they are typically focused on design instead of providing a foundation in basic or engineering sciences. Moreover, many students who enroll in environmental engineering programs have not participated in a biology course since their sophomore or junior year in high school. Our Environmental Biological Systems (EV396) course was designed to fill this gap by providing the engineering science that is later applied in environmental engineering design courses, such as Biochemical Treatment Processes (EV402). All environmental engineering majors must complete both courses, and many environmental science majors often complete EV396 as an elective. The foci of EV396, a prerequisite for EV402, are applied public health, microbiology, and microbial energetics. EV396 is considered a hybrid environmental biology course as it contains both environmental science and engineering topics. These courses help students to gain a solid grounding in fundamental biochemical processes in natural and engineered systems as applied to the practice of environmental engineering. These details and more on courses akin to EV396 are further discussed in detail in [10].

In an effort to focus students on fundamental principles in environmental engineering, the Environmental Engineering Program strives to integrate experiential learning into the curriculum. Students in EV396 complete a beer brewing laboratory exercise, which offers an interesting and engaging alternative to traditional course lecture on the glycolysis and fermentation metabolic processes. This exercise provides environmental engineering students with a stimulating experience to carry out a detailed fermentation experiment resulting in a familiar product. Equally important, this exercise further illustrates the importance of using precise aseptic laboratory techniques, while requiring students to apply fundamental knowledge of environmental science and biology to successfully brew a safe and appealing alcoholic product. EV396 deliberately follows another course focused on environmental chemistry that all environmental engineering students are required to take during their sophomore year. This sequential ordering further leverages experiential learning methods to help link together everyday life experiences of college students with important scientific and engineering processes that they must understand as part of their chosen discipline. Furthermore, because fermentation plays a critical role in many microbial processes in both natural and engineered systems to include anaerobic decomposition in swamps, wetlands, cow rumens, food production, landfills, and domestic and hazardous waste treatment facilities, it follows that environmental engineering students must be acutely aware of critical factors influencing the efficacy of this environmental process in a variety of biological systems. Moreover, environmental engineering students are 
charged to learn not only how these biological systems function, but also how they can be engineered and controlled to benefit society.

This study explains how the beer brewing experience can be utilized to link a variety of classroom fundamentals and activities with common environmental engineering practices. Historical assessment and evaluation of how well this experiential learning laboratory supports course objectives and ABET Student Outcomes and Program Criteria are discussed in detail.

\section{The Laboratory Experience}

The fermentation laboratory centers on giving students a unique and stimulating experiential learning opportunity to both engage and pique their interest in a key environmental engineering process. This laboratory experience familiarizes students with engineering concepts related to the fermentation process and illustrate its linkages to other daily activities. The five main educational objectives environmental engineers should gain from this laboratory exercise are:

1. Familiarization with substrates that serve as a carbon source and energy source for fermentation

2. Familiarization with engineered techniques used to make a system anaerobic

3. Familiarization with engineered procedures to clarify a supernatant from a solidliquid

4. Able to analyze the efficacy of fermentation with standard water quality parameters

5. Able to estimate the concentration of substrate (electron donor) required to achieve a specific yield

These objectives balance the engineering behind the beer brewing process and the chemistry involved in the process itself. While the first three objectives are currently qualitatively assessed during the laboratory execution by the instructor as well as during our post-fermentation laboratory survey given to students to assess learning from the exercise, there is potential to develop more quantifiable learning objectives for this laboratory. The final two objectives are quantitatively assessed by questions in the written laboratory report where students are required to analyze measured variables and calculate concentrations.

\section{Laboratory Execution}

The beer brewing laboratory was designed to provide students with a hands-on approach to understanding the fermentation process in a two-part experiment. Each segment is currently designed to be accomplished by teams of four to five students within a two-hour block. In the laboratory experiment, each team is asked to complete the brewing process on a small scale utilizing one-gallon small batch homebrew kits purchased from Northern Brewer (Roseville, $\mathrm{MN}$ ). Each team selects from a variety of different styles of homebrew kits that fit the following criteria: single-step fermentation process (14 days in length), fermentation temperature range of $60-75^{\circ} \mathrm{F}$, and wort boil time not exceeding 45 minutes. Before each laboratory session, the facility, equipment, and analytical instrumentation are prepared and sterilized utilizing a foodgrade sanitizing solution. As an additional safety measure, this particular laboratory is conducted in a geology lab, which does not run any other biology experiments. Students are informed about the sterile conditions that must exist and the aseptic techniques that they must employ during the 


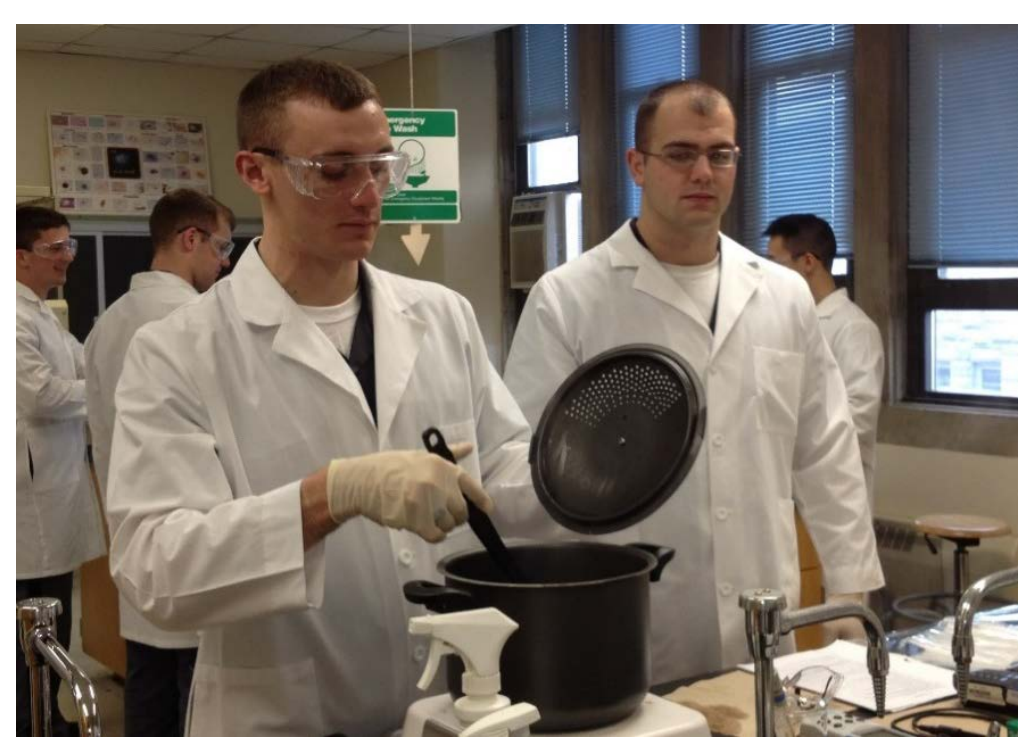

Figure 1. EV396 students boiling the wort which sterilizes the mixture and allows the sugars to dissolve and hops to condition the flavor and aroma of the finished beverage. execution of the laboratory to brew a safe, successful product.

Disinfection and sterilization of the laboratory space and equipment links to other methods of disinfection used in water treatment and sterilization in public health applications by environmental engineers.

During the first part of the laboratory, each team follows the provided instructions to create a sufficient wort solution. Students must add the malt extract, an essential step to the beer brewing process, because it serves as the carbon and energy source addressed by the first laboratory

objective. During the 45-minute wort boiling process (see Figure 1), instructors may ask a series of probing questions about what the students have just completed in aseptically producing the wort solution. This helps to maximize student learning by linking key concepts covered previously in the classroom to the actual application in the fermentation exercise.

Creating the wort solution (see Figure 2) through adding ingredients and boiling relates to other environmental engineering applications, such as anaerobic digestion in wastewater treatment and natural environmental systems. See Appendix A for complete procedural details for both portions of the laboratory. Students are reminded about the importance of using aseptic techniques throughout the execution to avoid spoiling the final product. Following the yeast addition, students must affix a screw cap and airlock chamber to the top of each fermentation vessel and additional questions are asked by the instructor to ensure students understand how and why the airlock chamber is designed to create a sterile and anaerobic environment by allowing carbon dioxide $\left(\mathrm{CO}_{2}\right)$ generated by the yeast to escape the fermenter without the addition of air containing oxygen and impurities. This querying supports the completion of the second laboratory objective. The first portion of this lab concludes with the beginning of a two-week fermentation process. The two-week active fermentation process taking place in an engineered fermenter system links to environmental

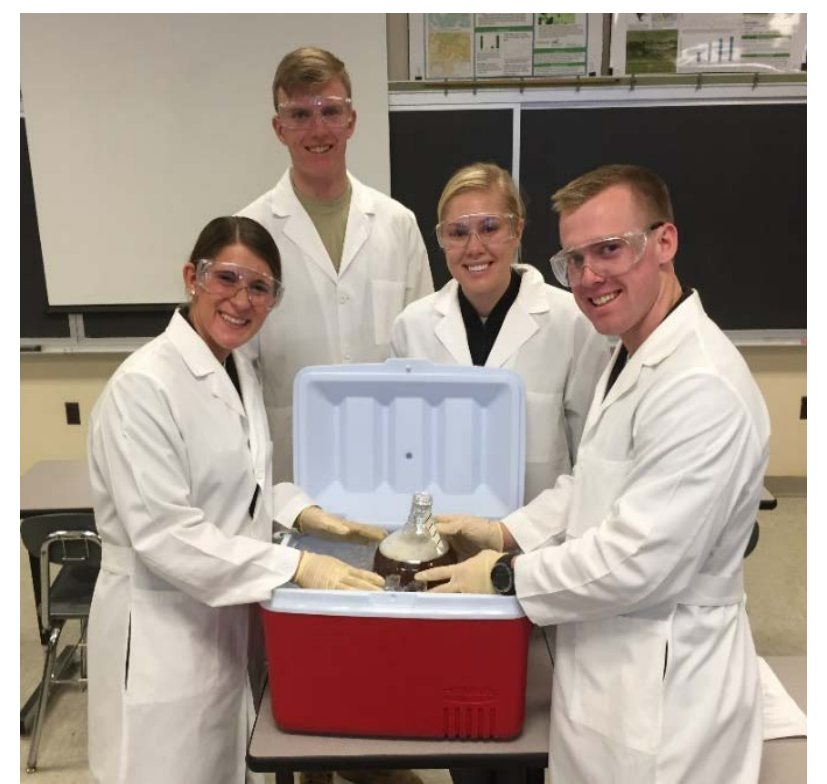

Figure 2. EV396 students cooling the wort mixture in preparation for transfer to the glass fermenter and pitching the yeast. 


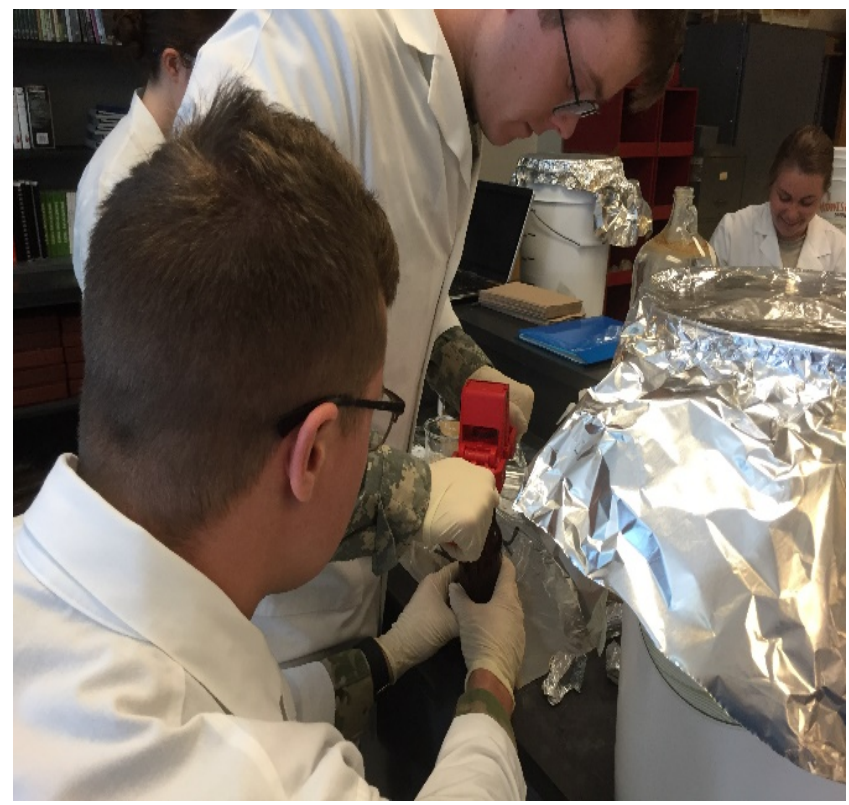

Figure 3. EV396 students aseptically capping their final beer products after adding sugar tablets for bottle conditioning. engineering applications, such as maturation of a landfill or certain biological wastewater treatment processes.

Once the fermentation process is complete, students return to complete the second portion of this laboratory exercise; bottling the beer. This is another hands-on opportunity for many students and generally receives the most praise by students as an interesting and unique experience. Before bottling, students must transport the fermentation vessels to each lab bench carefully to minimize mixing of the supernatant. Linking to how weir systems within sedimentation basins function to capture the cleanest water near the surface, students use an auto-siphon and hose to transfer the clarified supernatant near the surface of the fermenter solution to the bottling bucket leaving behind the undesired solids settled on the bottom of the vessel. This technique provides a functional experience to achieve the third laboratory objective by completing a successful solid-liquid separation.

The bottling process involves placing a single tablet of conditioning sugar into each bottle. The addition of small amounts of sugar is called bottle conditioning, which can induce secondary fermentation in each bottle, generating $\mathrm{CO}_{2}$ to naturally carbonate the beer. This procedure links to environmental engineering applications in water softening and conditioning. During this portion of the lab, students aseptically seal each bottle using a capper and affix their previously designed team labels (see Figures 3 and 4). The students are encouraged to think creatively by designing original labels that include a name, logo design, and slogan. The overall creativity of the team label is included in the scoring during the beer tasting competition.

Throughout the two-part laboratory experiment, samples are collected for analytical testing to monitor and determine the efficacy of the fermentation process as stated in the fourth laboratory objective.

Environmental engineering students are required to assess the following parameters: $\mathrm{pH}$, conductivity $(\mu \mathrm{S} / \mathrm{cm})$, specific gravity, potential alcohol (\%), refractive index (Brix), and UV absorbance and transmittance. The expected results should not vary much between teams regardless of the beer recipe

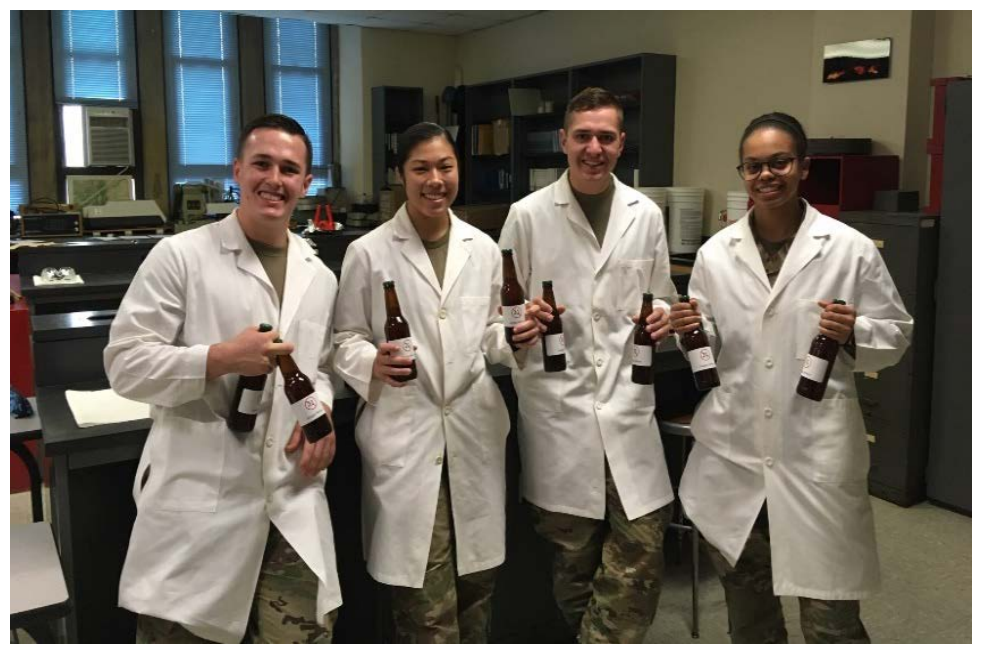

Figure 4. EV396 students posing with capped beer products. 
selected. $\mathrm{pH}$ should decrease throughout the experiment due to the production of carbonic acid associated with the $\mathrm{CO}_{2}$ produced by the yeast during fermentation. Overall conductivity should display a decreasing trend because ionic species are converted into $\mathrm{CO}_{2}$ and a host of uncharged reduced compounds. A Cary $60 \mathrm{UV}$-Vis Spectrophotometer measures each sample for particulate organic matter at a wavelength of 254nm. The change in UV254 readings indicates the conversion of particulate organic matter into dissolved organic matter; thus, a reduction in UV254 in this case represents the transformation of the carbon source by the microbial population. The results from the specific gravity, potential alcohol, and refractive index are utilized to determine the projected alcohol production and the efficacy of the yeast population during the formation process. The data collected from the hydrometer is used to calculate both theoretical and actual ethanol content during the laboratory experiment. Students demonstrate understanding by discussing and interpreting these analytical tests and calculating subsequent results to satisfy the final laboratory objective and produce the technical report.

\section{Fermentation Laboratory Evolution}

The fermentation laboratory was first integrated into EV396 in 2004, a year after the course inception in 2003. The laboratory exercise remained relatively consistent until 2013 with the addition of a new laboratory technician. Over the past 6 years, the laboratory experiment has been refined to further increase student educational opportunities. When the fermentation process was first introduced as a teaching tool, the original laboratory method was to divide the ingredients from a five-gallon brewing kit into fifths to create smaller one-gallon batches for each team. The benefit is that students were able to compare the same analytical data that currently varies between student teams. The significant disadvantages to this earlier method are keeping the ingredients sterile, poor product quality, no variation in beer types, and the lack of student choice in the product.

To address these challenges, the fermentation laboratory evolved in 2013 to use one-gallon small batch homebrew kits purchased from Northern Brewer. A trial run was implemented during the first year in which the instructors selected only two different styles of homebrew kits to verify the adjusted method adequately dealt with the challenges mentioned before. The primary challenge which arose after switching to one-gallon kits was the limitation on laboratory time for completion. By developing standard criteria - single-step fermentation process (14 days in length), fermentation temperature range of $60-75^{\circ} \mathrm{F}$, and wort boil time not to exceed 45 minutes - for each team brew kit, this laboratory exercise could now be completed within a practical time length. Implementing more process control $[11,12]$ in this laboratory allowed this exercise to be accomplished within the two-hour time limit. Additionally, students now had the ability to select from up to 12 different small batch recipes depending on availability. Evolving this laboratory exercise to use smaller one-gallon brew kits facilitated keeping the ingredients sterile, improved overall product quality, enabled student choice, and allowed for more exposure to different aromas, flavors and impacts of variations in types of gain and hop aiding in the depth of students' knowledge of the beer brewing process. Changing variety helps keep the fermentation laboratory fresh and exciting with the choice of different beer products and flavors each year. By developing the aspect of choice students gain a sense of ownership which aids in building respect for the craft opening an educational opportunity to talk about responsible consumption of alcohol. 
In 2015, an official beer tasting competition was introduced to help motivate teams to instill creativity and pride into their products as well as incorporate design, which is a key component to any engineering discipline. Additionally, this social event aimed at invoking friendly competition between teams while building comradery amongst the environmental engineering students. The competition was designed to enhance the student's depth of knowledge and commitment to producing a quality product. Knowing that their beer product will be judged next to that of their peers, students felt added motivation to compete as well as they can. The addition of this healthy competition also builds upon a fundamental goal of West Point, i.e., cultivate a winning atmosphere. The beer tasting competition has since evolved and grown to include not only key leadership within the Environmental Program, but faculty from across the entire Geography and Environmental Engineering Department. By joining with West Point's student chapter of the Engineers and Scientists for a Sustainable World club, this competition now involves all environmental engineering and science majors within the Environmental Program.

Better utilization of the downtime periods during the laboratory execution itself by instructors is critical to maximizing student learning potential. At the beginning of the beer brewing laboratory, specifically when allowing the wort, consisting of steeping grains, malt sugar extracts, and hops, to boil for roughly 45-60 minutes, there exists an ample opportunity to query students and discuss with them the processes currently taking place and how these processes will impact subsequent operations. This is an excellent opportunity to inquire about the variety of experimental tests and measurements the students will later conduct to assess the efficacy of their group's fermentation processes. Here, some students may be unfamiliar with the significance of specific testing methods and how the actual measurements link to one another. Discussions may also ensue regarding the engineered system to help maintain anaerobic conditions during the 2week fermentation process as well as the other various pieces of laboratory testing equipment. Previous classroom discussions using the number-line method [13] to explain certain reductionoxidation reactions enable strengthening of student's understanding of the key electron donors and acceptors driving chemical and biological reactions during the fermentation process. These discussions may significantly enhance the experiential learning portion of the fermentation fundamentals previously learned in a classroom lecture. Furthermore, these key discussions may help some students stay fully engaged in the laboratory and gain greater understanding than they otherwise would sitting and waiting for the wort boil to finish.

Periods of downtime during this laboratory are also crucial for individual and group reflection on the overall fermentation process and how this exercise links to their chosen profession as environmental engineers. Students from each group are encouraged to communicate with the other student groups and observe and inquire regarding some of the differences across the variety of beer flavors and types being brewed, giving them a better appreciation for the range of ingredients used and their impacts on the brewing processes.

\section{Experiential Learning Through Brewing Beer}

The fermentation laboratory exercise is an experiential learning opportunity that allows students to demonstrate their knowledge of this critical process in a practical application. Hands-on, active learning environments strengthen one's ability to learn fundamental principles leading to lifelong understanding (see Figure 5). [14] discusses three significant impacts that laboratory experiences have on undergraduate students - student engagement, positive impacts on industry, and personal and professional growth in their discipline. 
While traditional classroom lecture and presentation are valid methods to introduce the principles of fermentation, the deeper, more detailed understanding of this process flourishes during the laboratory experience itself. Indeed, this experiential learning exercise not only allows students to gain a more profound understanding of the fermentation process, but also the factors that impact this metabolic process and the technical methods needed to measure its efficacy. As part of this experiential learning process, students must also demonstrate an ability to operate and regulate an engineered system to ensure a successful and safe product. The experiential learning gained from this type of laboratory cannot be matched from merely reading a textbook or viewing a digital presentation. Students regularly express their excitement and appreciation for this type of

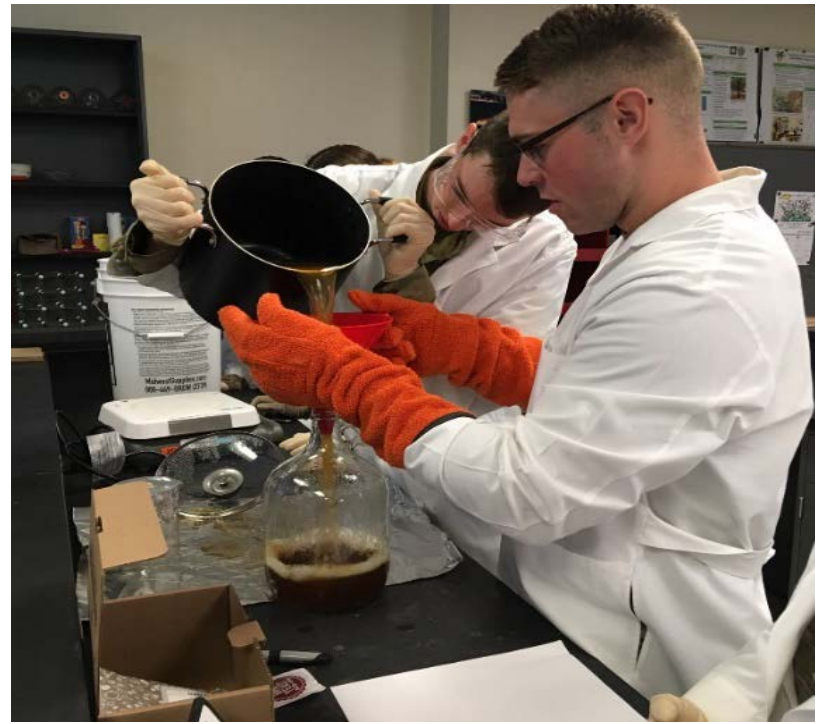

Figure 5. EV396 students engaged in hands-on learning while aseptically transferring the prepared wort mixture into a glass fermenter where the 14-day fermentation process will ensue. hands-on, immersive exercise where they can work as teams to create a tangible finished product. Figure 6 presents several critical connections between beer brewing and common environmental engineering processes.

The competitive nature of our students lends itself very well to this laboratory as student feedback from both portions of the laboratory execution indicates that they do focus their efforts to produce the best beer in hopes to surpass other peer products. Feedback received from a student survey following the beer tasting competition also supports that student motivation to do their best in following laboratory procedures resulted somewhat from knowing about the beer tasting competition. Eighteen of eighteen students agreed or strongly agreed on this survey that this healthy competition between student groups was a positive experience.

\section{The Final Report}

To complete the fermentation laboratory exercise, each student must submit a final technical report which thoroughly assesses their understanding of the overall fermentation process and how this process relates to brewing beer. The report requires students to explain selected aspects of the alcoholic fermentation process, to include the engineered airlock system and anaerobic requirements of the fermentation vessel as well as the addition of sugar during the bottling procedures. They must further explain the fermentation results they would expect to see if the airlock failed and justify these results. Students must explain how and why the measured specific gravity, refractive index, $\mathrm{pH}$, conductivity, and UV254 absorbance and transmittance values indicate the efficacy of the fermentation process carried out during the 14-day fermentation period. Calculations involve fermentation efficacy, specific gravity and yield, and scaling from bench experiments to commercial production. Using both stoichiometric reactions and their measured quantities of ingredients, students must further calculate the maximum theoretical along with the actual alcohol content. Lastly, students must critically think about and propose reasons for 


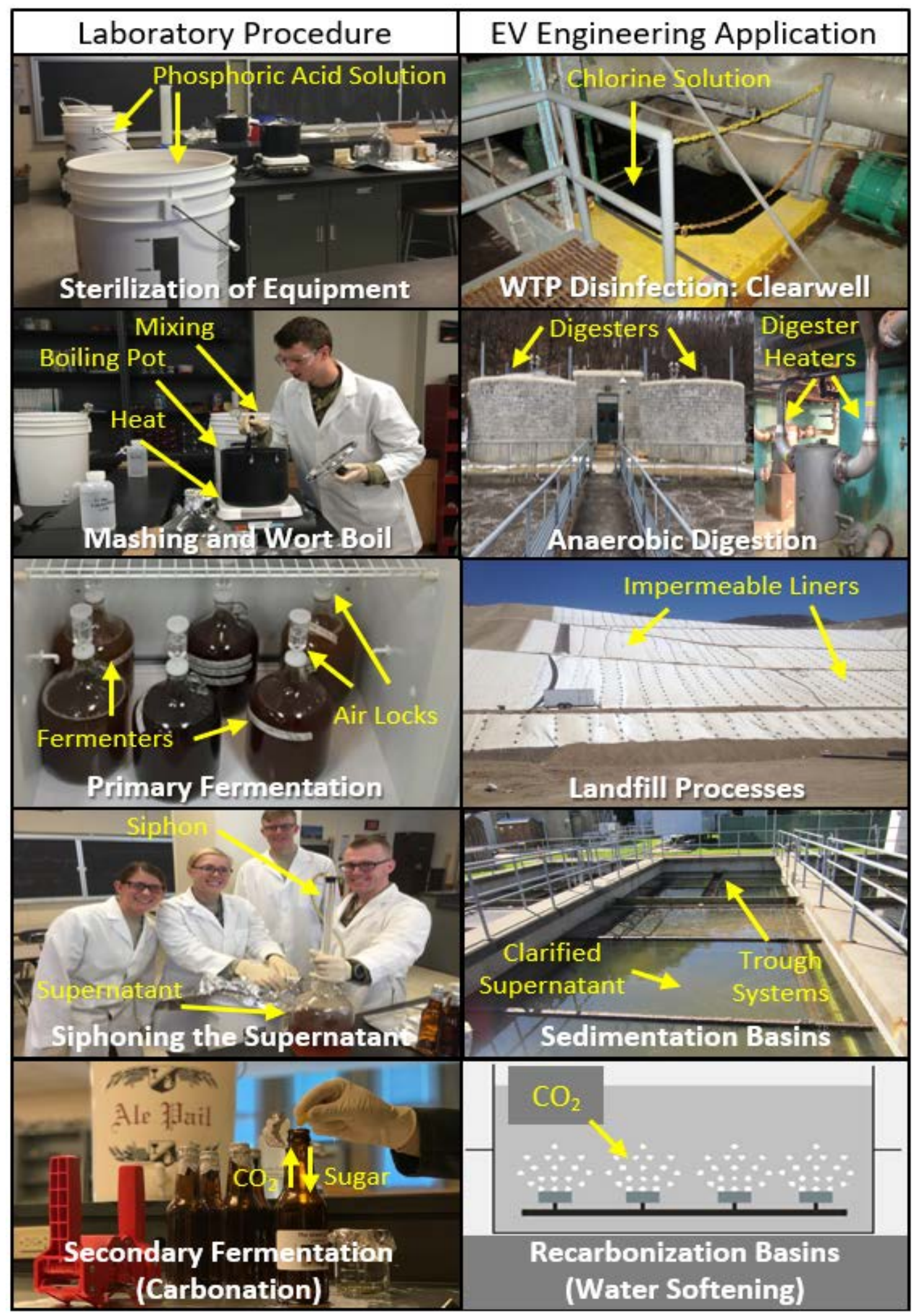

Figure 6. Linkages between beer brewing processes (left column) and key environmental engineering processes (right column). 
differences among calculated and measured values. Student answers and justifications indicate the level of understanding each has gained from the experiential learning.

Figure 7 shows the current fermentation laboratory report questions with corresponding Likertscale performance results from 2018. This laboratory report fully supports the newly refined ABET Student Outcome 6 by challenging students to demonstrate "an ability to develop and conduct appropriate experimentation, analyze and interpret data, and use engineering judgment to draw conclusions.” This report, reinforced by formal classroom instruction and detailed discussions during the laboratory execution, gives students a robust foundation for learning, applying, and understanding this critical environmental microbial process.

\begin{tabular}{|c|c|c|c|}
\hline Laboratory Report Question & $\begin{array}{c}\text { Average Points } \\
\text { Achieved }\end{array}$ & $\begin{array}{c}\text { Corresponding } \\
\text { Likert Score }\end{array}$ & $\begin{array}{l}\text { Principles and Practices of } \\
\text { Environmental Engineering }\end{array}$ \\
\hline $\begin{array}{l}\text { 1. Explain how air was excluded from the fermentation vessel. Can this be } \\
\text { applied on a larger scale? }\end{array}$ & $1.5 / 2.0$ & 3.75 & Biological Nutrient Removal \\
\hline $\begin{array}{l}\text { 2. Would you expect to see changes in the post experiment alcohol reading } \\
\text { if air was allowed to enter the fermentation vessel? Explain. }\end{array}$ & $1.67 / 2.0$ & 4.17 & $\begin{array}{l}\text { Aerobic Degradation (Activated } \\
\text { Sludge Process) }\end{array}$ \\
\hline 3. Why was sugar added to the bottles prior to capping? & $1.64 / 2.0$ & 4.10 & Water Softening \\
\hline $\begin{array}{l}\text { 4. Calculate the change (pre- and post-experiment) in specific gravity, } \\
\text { refractive index (Brix), and potential alcohol for your group and for the class } \\
\text { average. }\end{array}$ & $2.72 / 3.0$ & 4.54 & Water Quality Analysis \\
\hline $\begin{array}{l}\text { 5. Explain why changes in the specific gravity and refractive index can be } \\
\text { used to estimate the alcohol content. }\end{array}$ & $1.44 / 2.0$ & 3.61 & Sludge Dewatering and Management \\
\hline $\begin{array}{l}\text { 6. Estimate the maximum theoretical ethanol content based on the quantity } \\
\text { of sugar added and the reaction pathways discussed in class for glycolysis } \\
\text { and ethanol fermentation. Assume the following: mass of fermentable } \\
\text { glucose added is } 42 \% \text { of the dry or liquid malt extract added, the density of } \\
\text { ethanol is } 789 \mathrm{~g} / \mathrm{L} \text {, and the total volume is } 1 \text { gallon. Report your answers in } \\
\mathrm{g} / \mathrm{L} \text { and in percent by volume. }\end{array}$ & $15.03 / 16.0$ & 4.70 & $\begin{array}{l}\text { Environmental Chemistry } \\
\text { (Stoichiometry) and Dimensional } \\
\text { Analysis }\end{array}$ \\
\hline \multicolumn{4}{|l|}{$\begin{array}{l}\text { 7. Estimate the actual ethanol content of your product as a function of the } \\
\text { quantity of sugar added and the initial and final refractive index (Brix). }\end{array}$} \\
\hline 7a.How can you use the Brix readings to estimate percent sugar used? & $2.94 / 4.0$ & 3.68 & Analytical Chemistry \\
\hline $\begin{array}{l}\text { 7b. Estimate the actual ethanol content of your product based on the Brix } \\
\text { readings. Report your answer in } \mathrm{g} / \mathrm{L} \text { and percent by volume. }\end{array}$ & $6.78 / 8.0$ & 4.24 & Analytical Chemistry \\
\hline $\begin{array}{l}\text { 8. Explain why the theoretical results might differ from the experimental } \\
\text { measurements. }\end{array}$ & $2.5 / 3.0$ & 4.17 & Uncertainty Analysis \\
\hline $\begin{array}{l}\text { 9. Explain how and why pH, UV254 and conductivity changed as a result of } \\
\text { fermentation }\end{array}$ & $1.81 / 3.0$ & 3.01 & Data Analysis \\
\hline Completed Data Sheets & $8.75 / 10.0$ & 4.38 & Development of Lab Practices \\
\hline Overall for Laboratory Report & $46.78 / 55.0$ & 4.25 & \\
\hline
\end{tabular}

Figure 7. Evaluation of 2018 student performance on the fermentation laboratory report questions linked to specific environmental engineering processes. Scores are based upon a Likert scale from 1 to 5 where 5 relates to $100 \%$. The final column shows the linkages that exist between the lab report questions and the related principles and practices of environmental engineering. (n

\section{Results and Assessment}

Academic programs must strive to maximize student learning by consistently gathering and analyzing student and course results in order to assess the need for course adjustments and identify areas to improve and refine course methods and approaches to the material. Course surveys continue to be an effective instrument to encourage student feedback in the classroom 
while gauging each student's individual assessment of achieving key course objectives and academic goals. Consider the following excerpts taken from the 2018 EV396 end-of-course survey:

"The lab exercises in this course really helped me to grasp the concepts and material at a deeper level. I really liked the beer brewing lab because it showed us the science behind something that we all have seen before in everyday life."

"The fermentation lab definitely clarified my understanding on the topic."

"The lab assignments were a good opportunity to get real hands-on training to familiarize ourselves with the equipment that we might be expected to use in our discipline."

\section{- EV396 Environmental Engineering Students}

Continually striving to improve our courses and maximize student achievement, West Point's Environmental Engineering Program has decided to implement two new course surveys focused on the fermentation laboratory to evaluate and assess the beer brewing experience we provide to students. The first survey will assess student understanding of the fermentation process prior to classroom instruction and the laboratory experience. The second survey will reassess student understanding of fermentation after submission of the final laboratory report. We hope to evaluate the overall impacts of classroom instruction compared to the experiential learning exercise itself. A key focus of this critical assessment is to determine how well this fermentation laboratory supports ABET accreditation, namely the newly refined Student Outcomes and Program Criteria.

\section{Supporting ABET Accreditation}

EV396 directly supports ABET Student Outcomes (SO). Prior to the recent change in ABET SO to 1 through 7, EV396 directly supported ABET SO a (apply knowledge of mathematics, science, and engineering), b (design and conduct experiments, as well as to analyze and interpret data), g (communicate effectively), and i (recognition of the need for, and ability to engage in lifelong learning). Specifically, the fermentation laboratory provides 55 points toward the total 143 points in support of ABET SO b. Based upon a longitudinal review of support to ABET SO b from academic year (AY) 2012 to 2018, there is a strong correlation between beer brewing laboratory average grades and ABET SO b support (see Figure 8). Based on the newly revised ABET Student Outcomes and Program Criteria, the fermentation laboratory helps support ABET SO 6 ("an ability to develop and conduct appropriate experimentation, analyze and interpret data, and use engineering judgment to draw conclusions") as well as Program Criteria 11 ("Conduct laboratory experiments and analyze and interpret the resulting data in the environmental engineering focus area of water") and 13 ("Conduct laboratory experiments and analyze and interpret the resulting data in the environmental engineering focus area of environmental health”). 


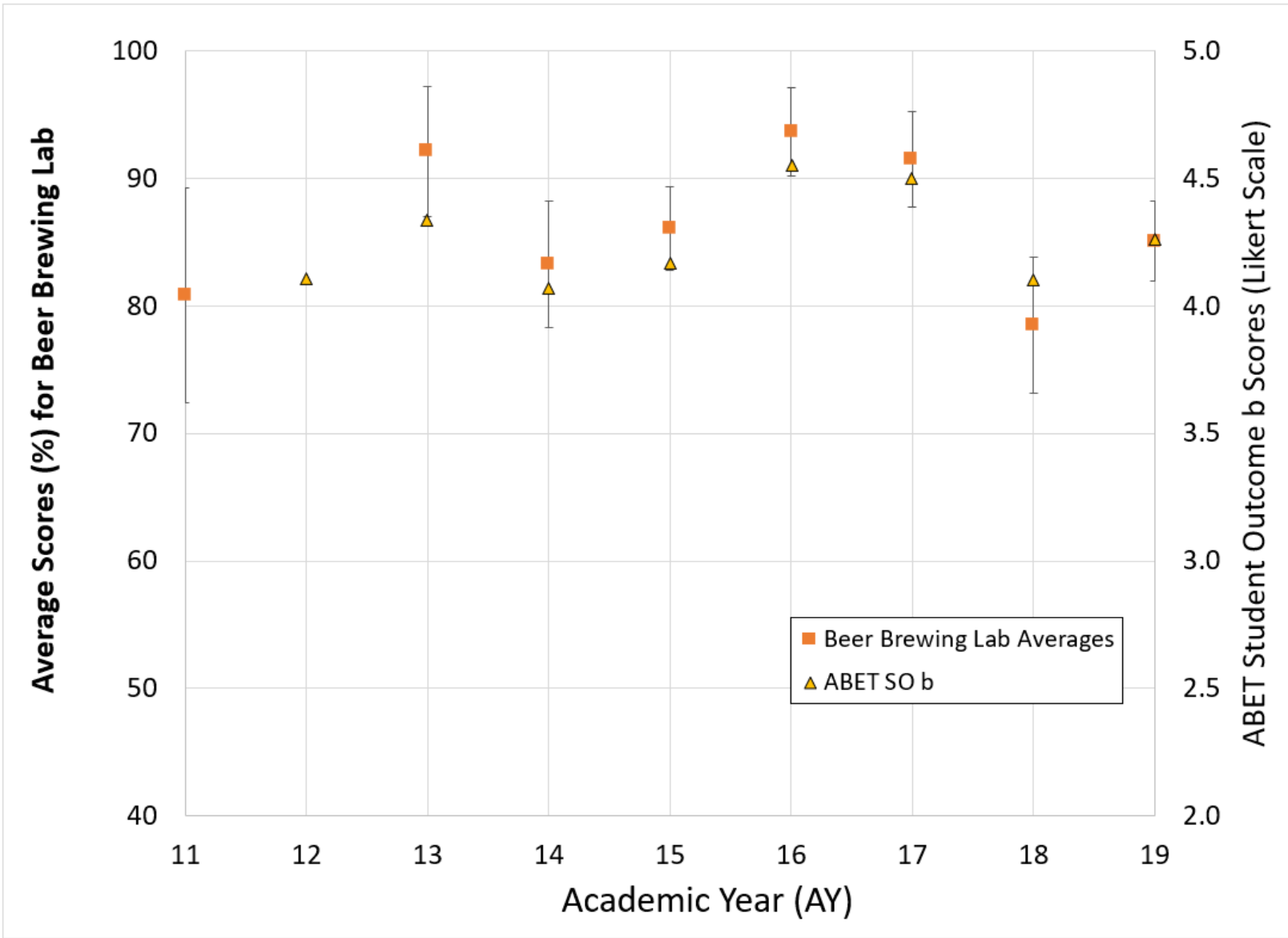

Figure 8. Evaluation of average scores associated with performance on the beer brewing lab and quantitative support to ABET Student Outcome b. Evaluation of this Student Outcome is based upon a Likert scale from 1 to 5 where 5 relates to $100 \%$.

The Course Survey - Are We Missing Any Ingredients?

As previously mentioned, a new course-wide survey was developed and implemented during the fall 2018 semester to evaluate and assess the current laboratory experience among our students and whether this exercise is an effective tool for students to achieve the desired learning objectives and outcomes. This survey was given directly following student submission of the final laboratory report. Using the 5-point Likert scale, with 5 indicating greatest achievement, this survey assessed two primary domains of fermentation instruction in EV396: first, the extent to which classroom instruction prepared students for the experiential learning portion in the laboratory; and second, how well the laboratory experience resulted in students achieving specific laboratory objectives. The third portion of the survey consists of three free-form response questions which solicit feedback and recommendations from the students as well as a question asking specifically which, if any, previously taken courses contributed to their understanding of the fermentation laboratory. This final question will be utilized to draw and assess key linkages to preceding environmental engineering curriculum courses as well as to other freshman and sophomore introductory courses. Figure 9 shows the newly implemented post-fermentation survey questions and the overall Likert-scale results from our students in 2018. This survey has already given instructors meaningful feedback, helping them to determine 


\begin{tabular}{|c|c|c|}
\hline Post-Laboratory Survey Question & $\begin{array}{c}\text { Corresponding Likert } \\
\text { Score (Std Dev) }\end{array}$ & Score Breakdown \\
\hline \multicolumn{3}{|l|}{ Part l - From classroom lecture on the Fermentation Process, I can } \\
\hline $\begin{array}{l}\text { a. Clearly explain the overall purpose and function of fermentation in } \\
\text { metabolic processes }\end{array}$ & $4.06( \pm 0.54)$ & $0 \times \mathrm{SD} / 0 \times \mathrm{D} / 2 \times \mathrm{N} / 13 \times \mathrm{A} / 3 \times \mathrm{SA}$ \\
\hline $\begin{array}{l}\text { b. Identify and discuss examples of fermentation in natural and engineered } \\
\text { environmental systems (i.e., Digesters, Wetlands, etc). }\end{array}$ & $3.86( \pm 0.48)$ & $0 \times \mathrm{SD} / 0 \times \mathrm{D} / 3 \times \mathrm{N} / 14 \times \mathrm{A} / 1 \times \mathrm{SA}$ \\
\hline $\begin{array}{l}\text { c. Discuss how fermentation links to other important cellular metabolism } \\
\text { processes (i.e., glycolysis). }\end{array}$ & $4.11( \pm 0.76)$ & $0 \times \mathrm{SD} / 1 \times \mathrm{D} / 1 \times \mathrm{N} / 11 \times \mathrm{A} / 5 \times \mathrm{SA}$ \\
\hline d. Discuss important cellular waste products from fermentation processes. & $3.67( \pm 1.03)$ & $0 \times \mathrm{SD} / 3 \times \mathrm{D} / 4 \times \mathrm{N} / 7 \times \mathrm{A} / 4 \times \mathrm{SA}$ \\
\hline $\begin{array}{l}\text { e. Discuss the expected reaction rate and biomass yield of a fermentation } \\
\text { reaction relative to an aerobic reaction. }\end{array}$ & $3.81( \pm 0.52)$ & $0 \times \mathrm{SD} / 0 \times \mathrm{D} / 4 \times \mathrm{N} / 13 \times \mathrm{A} / 1 \times \mathrm{SA}$ \\
\hline $\begin{array}{l}\text { f. Able to identify and describe examples of fermentation involved in } \\
\text { Environmental Engineering. }\end{array}$ & $3.83( \pm 0.51)$ & $0 \times \mathrm{SD} / 0 \times \mathrm{D} / 4 \times \mathrm{N} / 13 \times \mathrm{A} / 1 \times \mathrm{SA}$ \\
\hline \multicolumn{3}{|l|}{ Part 2 - From the Fermentation Lab exercises, I am } \\
\hline $\begin{array}{l}\text { a. Familiar with substrates that serve as a carbon source and substrates that } \\
\text { serve as an energy source during fermentation. }\end{array}$ & $3.28( \pm 0.83)$ & $0 \times \mathrm{SD} / 4 \times \mathrm{D} / 5 \times \mathrm{N} / 9 \times \mathrm{A} / 0 \times \mathrm{SA}$ \\
\hline $\begin{array}{l}\text { b. Familiar with engineered air-lock systems used to make a system } \\
\text { anaerobic by limiting mass transfer of gasses into or out of the system. }\end{array}$ & $3.61( \pm 0.85)$ & $0 \times \mathrm{SD} / 3 \times \mathrm{D} / 2 \times \mathrm{N} / 12 \times \mathrm{A} / 1 \times \mathrm{SA}$ \\
\hline $\begin{array}{l}\text { c. Familiar with engineered techniques to clarify a supernatant from a solid- } \\
\text { liquid suspension and quantify the efficacy of clarification by measuring } \\
\text { UV absorbance and transmittance. }\end{array}$ & $3.11( \pm 1.02)$ & $1 \times \mathrm{SD} / 4 \times \mathrm{D} / 6 \times \mathrm{N} / 6 \times \mathrm{A} / 1 \times \mathrm{SA}$ \\
\hline $\begin{array}{l}\text { d. Able to analyze the efficacy of fermentation (i.e., waste products } \\
\text { formed) by measuring common water quality parameters ( } \mathrm{pH} \text {, conductivity, } \\
\text { specific gravity, etc.). }\end{array}$ & $3.61( \pm 0.85)$ & $0 \times \mathrm{SD} / 3 \times \mathrm{D} / 2 \times \mathrm{N} / 12 \times \mathrm{A} / 1 \times \mathrm{SA}$ \\
\hline $\begin{array}{l}\text { e. Able to estimate sugar (electron donor) concentrations required to achieve } \\
\text { a specific yield (alcohol content) in the fermentation process. }\end{array}$ & $3.56( \pm 1.04)$ & $2 \times \mathrm{SD} / 0 \times \mathrm{D} / 3 \times \mathrm{N} / 12 \times \mathrm{A} / 1 \times \mathrm{SA}$ \\
\hline $\begin{array}{l}\text { f. Able to identify the mass flow rate required to increase the beer brewing } \\
\text { process from bench to commercial scale. }\end{array}$ & $2.83( \pm 0.99)$ & $2 \times \mathrm{SD} / 4 \times \mathrm{D} / 7 \times \mathrm{N} / 5 \times \mathrm{A} / 0 \times \mathrm{SA}$ \\
\hline
\end{tabular}

\begin{tabular}{|l|}
\hline \multicolumn{1}{|c|}{ Likert-Scale Key } \\
\hline 1 - Strongly Disagree (SD) \\
\hline 2 - Disagree (D) \\
\hline 3 - Neither (N) \\
\hline 4 - Agree (A) \\
\hline 5 - Strongly Agree (SA) \\
\hline
\end{tabular}

Figure 9. Results from 2018 evaluation of student responses on the post-fermentation course survey. Scores are based upon a Likert scale from 1 to 5 where 5 relates to $100 \%$. $(n=18)$

several minor course corrections to be implemented in following years to enhance student learning and achievement of desired laboratory outcomes.

In future semesters, another similar survey will be given before the fermentation block and laboratory exercise to assess student's initial understanding and outlook on fermentation and beer brewing. Survey results from the studies - pre and post fermentation laboratory - could then be compared to evaluate changes in student attitudes and performance regarding fermentation and its application in environmental engineering. [15] supports the use of pre- and post-laboratory surveys or assessments to help constructivist learning through assisting students to contextualize the laboratory objectives and then reflect upon what they had accomplished during the exercise. These focused surveys will add an additional layer of analysis and assessment to EV396 and our overall ABET accredited Environmental Engineering program by giving detailed feedback on student performance and overall comprehension of the course material as a result of this experiential learning opportunity. 


\section{The Beer Brewing Competition}

Having deep cultural roots in many regions of the world, the engineered process of brewing beer enables students to not only master the fermentation and disinfection processes, but also to appreciate beer in a scientific sense. Students, staff, and faculty voluntarily conduct a beer tasting competition following the completion of the fermentation and bottling processes. This annual event has become a favorite among both faculty and students, greatly helping to encourage teamwork, inspire creativity and motivation among our students, and build comradery between them. This event helped to foster stronger relationships among students and faculty beyond what is typically achieved in the classroom environment. Eighteen of eighteen participants surveyed following the beer tasting competition indicated that they agreed or strongly agreed that this event contributed to building comradery within and amongst students and faculty in the environmental program and the department. This event receives favorable student feedback year after year.

Participation in this event typically ranges from 20-40 judges, of which approximately two-thirds are students and one-third is staff and faculty. Additionally, 20-40 other students and several staff and faculty members attend who are either not old enough to legally consume alcohol or who choose not to consume alcohol; these attendees consume nonalcoholic beverages only.

The tasting scorecards typically assess the beers' appearance, aroma, flavor, and logo design. Judges evaluate the beers using this scorecard with a Likert-type scale with numbers and their associated meanings listed. Possible scores are 1 (very bad), 2 (bad), 3 (“OK”), 4 (good), and 5 (very good). Average scores are typically 2-5, with higher concentrations being 3-4. Judges’ samples are approximately 20-30 mL per beer batch, and there are generally five to eight brewed samples of beer. Each group produces eight bottles of beer in total. The remaining five to seven beers per group are then available to the participants of legal age. This generally leaves one or two bottles of beer remaining per participant. Food and nonalcoholic beverages are also served at the event.

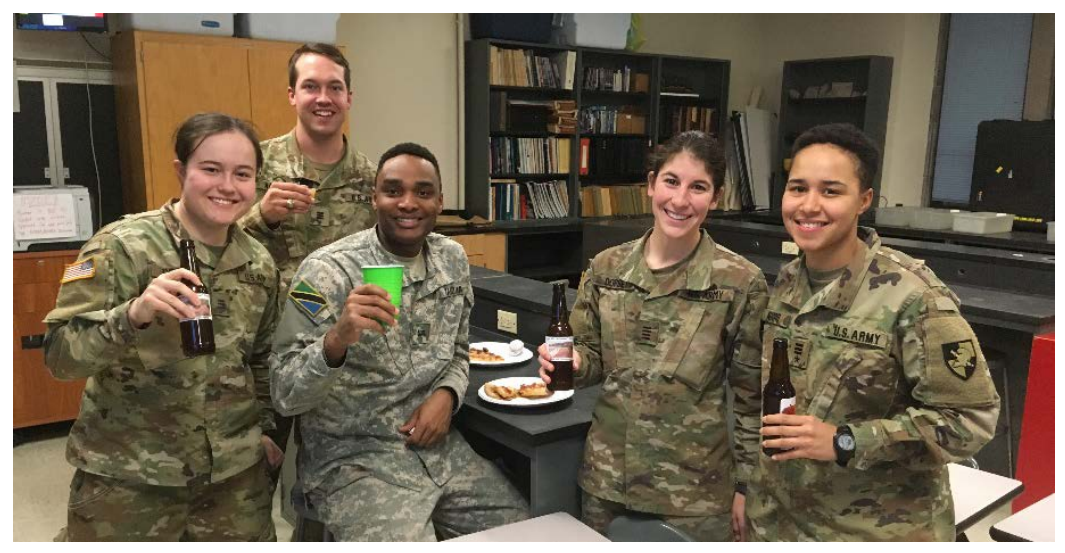

Figure 10. Students enjoying the finished beer products at the beer tasting competition
Because West Point is focused on grooming future leaders in our Nation's military, this event models safe, responsible alcohol consumption for our students. Staff and faculty supervise the event to ensure students act appropriately. There is intentionally not enough alcohol served to allow anyone to become intoxicated, and the beer is consumed slowly and socially with food (see Figure 10). Judging various characteristics of the beers also emphasizes the attention on the quality of product over quantity of alcohol. Additionally, this single event provides a powerful opportunity to expose students to the historical and social significance of brewing and consuming beer, and it gives faculty an opportunity to encourage responsible consumption and behavior with respect to alcohol. 


\section{Conclusion}

It is often through accomplishing everyday activities that we learn and acquire the basic skills and principles necessary to apply to other, more challenging problems and dilemmas we face. Brewing beer as an experiential learning tool lends itself to be a unique and effective method for educating environmental engineering students. Lending itself as a potential lifelong hobby, beer brewing could continue to refine and reinforce skills and principles used by environmental engineers and scientists in the field. It is incumbent upon institutional academic programs to provide experience-based learning opportunities for their engineering students which serves to build connections between the classroom and the real world. As educators, we have an opportunity with our students every day to generate and support links between scientific and engineering fundamentals that students must master and their everyday life. Accomplishing this will enable our students to develop their ability to become adaptive, innovative, and effective thinkers, able to solve the myriad of challenges that will face them in life and their chosen discipline. Textbooks and slide presentations can serve as useful tools to a certain point in the classroom, but without augmenting this classroom learning with experience through application, much of what is gained by students in the classroom may not endure throughout a student's subsequent career. In our ever more complex and dramatically changing world, future environmental dilemmas will require innovative solutions from our rising engineers. This innovation demands mastery in both understanding and applying science and engineering fundamentals - skill sets that are gained through deliberate and effective experiential, pragmatic learning opportunities.

\section{References}

[1] M. A. Butkus, M. C. Johnson, and J. C. Lynch, Linking Courses and Essential Experiences in an Undergraduate Environmental Engineering Curriculum: American Society for Engineering Education Annual Conference and Exposition, June 20-23, 2004, Salt Lake City, UT, USA.

[2] A. Mitchell and C. Savill-Smith, "The Use of Computer and Video Games for Learning, A Review of the Literature,” Learning and Skills Development Agency, 2004.

[3] B. K. Sato, U. Alam, S. J. Dacanay, A. K. Lee, and J. F. Shaffer, "Brewing for Students: An Inquiry-Based Microbiology Lab,” Journal of Microbiology \& Biology Education, vol. 16-2, pp. 223-229, Dec. 2015.

[4] D. J. Wood, "Beer Brewing as a Model for Improving Scientific Literacy in Higher Education,” Journal of the Human Anatomy and Physiology Science, vol. 20, no. 2, pp. 19-27, Apr. 2016.

[5] M. W. Pelter and J. McQuade, "Brewing Science in the Chemistry Laboratory: A "Mashing” Investigation of Starch and Carbohydrates,” Journal of Chemical Education, vol. 82, no. 12, pp. 1811-1812, Dec. 2005.

[6] J. N. Korolija, J. V. Plavsic, D. Marinkovic, and L. M. Mandic, "Beer as a Teaching Aid in the Classroom and Laboratory,” Journal of Chemical Education, vol. 89, pp. 605-609, Feb. 2012. 
[7] S. Farrell, R. P. Hesketh, J. A. Newell, and C. S. Slater, "Introducing Freshmen to Reverse Process Engineering and Design Through Investigation of the Brewing Process," International Journal of Engineering Education, vol. 17, no. 6, pp. 588-592, Jan. 2001.

[8] M. W. Pelter, "Brewing Science," Journal of Chemical Education., vol. 35, no. 5, pp. 48-52, March-April 2006.

[9] P. D. Hooker, W. A. Deutschman, and B. J. Avery, "The Biology and Chemistry of Brewing: An Interdisciplinary Course,” Journal of Chemical Education, vol. 91, pp. 336-339, Feb. 2014.

[10] M. A. Butkus and W. Epolito, Development of an Environmental Biological Course in an Undergraduate Environmental Engineering Curriculum: American Society for Engineering Education Annual Conference and Exposition, June 18-21, 2006, Chicago, IL, USA.

[11] S. S. Moor and P. R. Piergiovanni, Experiments in the Classroom: Examples of Inductive Learning with Classroom-Friendly Laboratory Kits: American Society for Engineering Education Annual Conference \& Exposition, June 22-25, 2003, Nashville, TN, USA.

[12] S. S. Moor and P. R. Piergiovanni, Inductive Learning in Process Control: American Society for Engineering Education Annual Conference \& Exposition, June 20-23, 2004, Salt Lake City, UT, USA.

[13] L. T. Plante, J. Starke, M. A. Butkus, E. Martinez, E. Grogan, and S. Grohs, Emphasizing Redox Fundamentals to Prepare Environmental Engineering Students for an Uncertain Future in Wastewater Treatment Standards: American Society for Engineering Education Middle Atlantic States Fall Conference, October 26-27, 2018, Brooklyn, NY USA. 2018.

[14] M. L. McDermott, "Lowering barriers to Undergraduate Research through Collaboration with Local Craft Breweries,” Journal of Chemical Education, vol. 93, pp. 1543-1548, Jul. 2016.

[15] M. Abdulwahed and Z. K. Nagy, “Applying Kolb’s Experiential Learning Cycle for Laboratory Education,” Journal of Engineering Education, vol. 98, no. 3, pp. 283-294, Jul. 2009. 


\section{Appendix A. Fermentation Laboratory Procedures (Part I and II)}

PART I (2 hours)

a. Part I Pre-Lab Procedures.

(1) One day prior to laboratory execution.

(a) Cover each of 4 glass fermenter bottles with beakers with aluminum foil, then autoclave them.

(b) Prepare 4-500ml bottles of sterilized water and mark as sterile water with tape.

(c) Wipe down lab benches with a $10 \%$ bleach solution - twice

(d) Sterilize all equipment that will be coming in contact with fermentation media.

(e) Set BOD incubator to $20^{\circ} \mathrm{C}$, or type-specific temperature, and make room for fermentation bottles.

(f) Lay out equipment and supplies.

(2) Day of laboratory execution.

(a) Prepare Grains.

1. Lightly crush grains in a plastic bag if applicable.

2. Place 4.7L of half deionized water and half tap water in a Teflon pot and bring to $68^{\circ} \mathrm{C}$.

3. Place grains in the provided grain-boiling bag and seep at $68^{\circ} \mathrm{C}$ for $* *$ min, if

applicable (never let the water get above this temperature; do not boil the grains).

(b) Using a cooler, obtain ice and place in at least four of the laboratory sinks (no sooner than 1 hour before the start of the lab). Two 1-gal bottles or two Teflon pots must fit in each cooler.

b. Part I Laboratory Procedures.

(1) Wash hands twice and put on apron, goggles and gloves.

(2) Bring the wort (solution of grain sugars and proteins) in the Teflon pot to a boil.

** Refer to kit instruction sheet at this point for specific ingredients, times, and quantities**

(3) Add the liquid malt extract and/or dry malt extract and hops according to the variety-specific instruction sheet. Hops may be added at multiple times during the boiling period. Those added near the start are called "bittering hops" and those added near the end are "flavoring hops".

NOTE: Do not put the lid on all the way, offset it slightly to let some steam out. BE CAREFUL OF BOIL OVERS, IT HAPPENS OFTEN. REMOVE COVER FREQUENTLY \& STIR so that the malt extract does not scorch on the bottom of your pot.

(4) Maintain at a rolling boil. The suspension may foam because of the protein content so stir it often to prevent boiling over. Near the end of the boil, fill a lab sink or use a tray with cold tap water and/or ice to be used as the initial cold-water bath.

(5) When the specified boiling period is complete, prepare the wort for fermentation.

(a) Turn off the heater plate. 
(b) Transfer the Teflon pot to cold water bath in a lab sink and cool to below scalding temperature.

(c) Once the wort is below scalding, add the wort to the cool water in the glass fermenter using a sterile funnel, and cover with sterile aluminum foil. It is beneficial to aerate the wort at this time.

(6) Place the fermentation vessel in the ice bath and cover with aluminum foil.

(7) Agitate the suspension once per minute for 10 minutes.

(8) Check the temperature by aseptically pipetting $10-15 \mathrm{~mL}$ of the wort into a $50 \mathrm{~mL}$ graduated cylinder.

(9) If the temperature is greater than $24^{\circ} \mathrm{C}$, then cover the fermenter, wait 10 minutes, and repeat the previous step.

(10) When the temperature is less than $24^{\circ} \mathrm{C}$ remove the fermenter from the ice bath and pour $120 \mathrm{ml}$ of the wort into a beaker.

(11) Add yeast to the wort in the fermenter as specified for the specific variety.

(12) Aseptically attach the trap to the stopper, fill trap with sterile water, and rest the stopper in the fermentation vessel spout.

(13) Insert the stopper in the fermentation vessel such that it seals. Do not push the stopper into the vessel!

(14) Label your glass fermentation vessel and place in the incubator set to the appropriate temperature. Ferment for two weeks (until Part II of the lab).

(15) When the sample in the beaker cools to $20^{\circ} \mathrm{C}$ (you may set the beaker in the ice bath to cool):

(a) Determine the specific gravity and potential alcohol (\%) of the wort with a hydrometer (handle the hydrometer with extreme care). Pour $80 \mathrm{~mL}$ of the wort in the beaker into the hydrometer cylinder. Before taking the reading, spin the hydrometer to remove bubbles that may form under the hydrometer. Take your reading by noting where the hydrometer scale crosses the air-water interface. Record your data in the attached table.

(b) Measure $\mathrm{pH}$ and conductivity of the wort using the sample in the hydrometer cylinder. Ensure only the glass portion of the probe is placed in the wort. Record your data in the Appendix table.

(c) Use the refractometer to measure the refractive index of the wort (on the Brix scale) by:

1. Placing 2-3 drops on the prism

2. Aim the prism towards the light and adjust the eye piece to focus

3. Read the number on the scale that corresponds to the interface between the blue and white boundaries

4. Clean the prism surface with DI water and the cloth provided.

(d) Pipette a sample of the wort from the beaker into a UV254 vial to measure UV absorbance (may require a 1:10 or a 1:100 dilution to achieve appropriate results).

(16) Clean all labware using the cleaning solution and place in the designated area.

(17) Wipe down the benches with the bleach solution twice. 
PART II (1.5 hours)

c. Part II Pre-Lab Procedures (To be completed by the laboratory EV Engineer).

(1) One day before laboratory Part II execution.

(a) Wipe down lab benches with a $10 \%$ bleach solution - twice

(b) Cover beer bottles with aluminum foil and autoclave. Sterilize enough aluminum foil to cover each bottling bucket by placing in an autoclave bag.

(c) Clean and sterilize capper, and caps in the 5th bottling bucket.

(d) Fill each of four bottling buckets with tap water and add cleaning solution. Sterilize capped end of siphon tube for 15 minutes and then reverse such that tubing is submerged and the capped end is above the surface. Cover capped end with sterile aluminum foil.

(e) Lay out equipment and supplies.

(2) Day of laboratory Part II execution.

Without mixing, move each fermentation vessel to the lab benches.

d. Part II Laboratory Procedures.

It is now time to bottle your product.

(1) Put on apron and goggles.

(2) Roll up sleeves, wash hands and arms twice, and put on sterile gloves.

(3) Use a sanitized auto-siphon and tubing to aseptically transfer the supernatant from the glass fermentation vessel to the five-gallon bottling bucket. Immerse the auto-siphon into the fermenter and pump the racking cane/piston assembly 1-2 times to start a siphon.

(4) An alternate aseptic method using a racking cane and siphon tubing is as follows:

(a) Cadet 1 will cover one end of the siphon tube (located at the bottom of the bucket) with thumb and slowly raise the end of the tube until the water level reaches the capped end of the siphon.

(b) (Steps b and c should be completed simultaneously) Cadet 2 will gently remove the stopper from the fermentation vessel and place the capped end of the siphon into the fermentation vessel (lower to approximately 1" from the bottom) while Cadet 1 lowers the other end into a $500 \mathrm{ml}$ glass beaker. Once the siphon is in position, Cadet 1 will remove his/her thumb and siphon the wastewater from the tube into the $500 \mathrm{ml}$ beaker. Once the supernatant reaches the end of the siphon re-cover the end of the siphon tube with thumb. Dispose of the fermenter wastewater.

(c) Meanwhile Cadet 3 will dump the water from the bottling bucket into the sink and place on a lab stool in front of the fermentation vessel.

(d) Cadet 1 will then siphon the supernatant into the bottling bucket.

(5) Cover the bucket with sterile aluminum foil and wait 10 minutes.

(6) Aseptically add carbonation tablets to each $12 \mathrm{oz}$ bottle.

(7) Using the tap on the bottling bucket, fill the $500 \mathrm{ml}$ beaker with $120 \mathrm{ml}$ of the supernatant.

(8) Measure specific gravity, potential alcohol, refractive index, pH, UV254 and conductivity of the wort in the same manner as Part I. Record your data in the Appendix table. 
(9) Using the tap on the bottling bucket, transfer the supernatant from the bucket to the bottles leaving approximately $3 / 4$ inch to one inch of head-space. Cap the bottles.

(10) Label the bottles with the label and your group name or place your group number on the top of the bottle cap.

(11) Give each bottle a shake to make sure the sugar is dissolved. Leave the bottles at room temperature for 1-2 weeks to condition.

e. Clean-up Procedures.

(1) Clean all glassware using the brush and cleaning solution provided and place in the designated area.

(2) Wipe down the benches with the bleach solution twice.

(3) Email your data to your instructor. DONT FORGET! 